\title{
RESENHA Estado, Políticas e Agenciamentos sociais em Saúde: etnografias comparadas
}

\author{
Matilde Quiroga Castellano ${ }^{1}$ \\ Universidade Federal de Santa Catarina
}

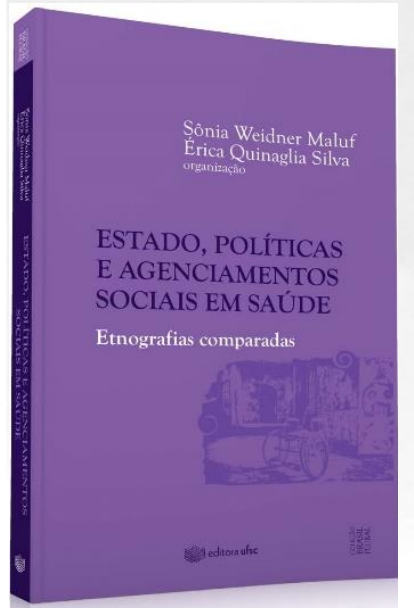

MALUF, Sônia Weidner; QUINAGLIA SILVA, Érica (org.). Estado, Políticas e Agenciamentos sociais em Saúde: etnografias comparadas. Florianópolis: Editora da UFSC, 2018. 293 p. 
$\mathrm{E}$ ste livro organizado pelas professoras Sônia Weidner Maluf e Erica Quinaglia Silva compõe, junto a outros dez volumes, a Coleção Brasil Plural, produzido através da parceria entre o INCT Brasil Plural e a Editora da UFSC, e que tem como objetivo dar notoriedade às pesquisas realizadas pelo Instituto Nacional de Pesquisa Brasil Plural.

Tal como descrito na sua apresentação, a proposta deste livro consiste em refletir ao respeito dos desafios e diálogos possíveis entre a antropologia e o Estado, em relação às políticas públicas e aos agenciamentos sociais no campo da saúde, através da recuperação e potencialização de experiências etnográficas nesse campo.

Antes de adentrarmos na composição deste livro, é preciso mencionar um conceito que é chave, além de outros que serão mencionados nos comentários sobre cada artigo, e que aparece explicitado na oitava pagina deste exemplar. Estou me referindo ao conceito de "agenciamento", segundo as autoras numa nota de rodapé:

não para substituir a ideia de agência, por ação ou prática social, mas para compreender essas práticas como constituídas por diferentes atravessamentos, cruzados por diferentes linhas de força, ou seja, como campos de força permeados por relações de poder. (MALUF e QUINAGLIA SILVA, 2018: 8)

Separado em dois grandes eixos: Parte I: Práticas do Estado, instituições, serviços, políticas públicas em saúde e Parte II: Agenciamentos e experiências sociais em saúde, o livro é resultado da colaboração de dezesseis autoras (escolho o uso do feminino respeitando a escolha das organizadoras) formadas em diferentes disciplinas, principalmente antropologia, psicologia e sociologia, e de diferentes estados do Brasil, compondo assim uma interessante bagagem multidisciplinar e multiterritorial.

A Parte I: Práticas do Estado, instituições, serviços, políticas públicas em saúde, tem como objetivo discutir as diferentes dimensões que envolvem as ações do Estado, suas práticas, políticas públicas instituições e serviços. Este eixo começa com o texto de uma das organizadoras do livro, Sônia Maluf, e cujo título é Biolegitimidade, direitos e políticas sociais: novos regimes biopolíticos no campo da saúde mental no Brasil. Durante este artigo, Maluf traz elementos para uma reflexão sobre o conceito de biolegitimidade, pensando o mesmo como "dispositivo de produção de direitos, de reconhecimento e de acesso a serviços e atendimento por parte do Estado, e também como meio de reivindicação e conquista de direitos". A autora revela este conceito como fundamental para analisar as políticas públicas no âmbito da saúde mental, utilizando como insumo uma experiência etnográfica situada em Santa Catarina.

O segundo artigo intitulado Gênero, raça e loucura: o perfil das mulheres que cumprem medida de segurança no Distrito Federal, foi escrito por outra das organizadoras deste livro, Érica Quinaglia Silva, em parceria com Josenaide Engracia dos Santos e Mônica Oliveira da Cruz. Através deste trabalho, as autoras refletem sobre as características das mulheres que cumprem medidas de segurança no Distrito Federal e a partir da análise do trinômio gênero-raça-loucura e do questionamento do termo "loucura", problematizam as tensões entre uma perspectiva punitivista e uma perspectiva do cuidado. 
Michelle Camargo, no seu artigo Dentre muros: a trajetória de um hospital psiquiátrico, através do resgate das memórias de Benedita Fernandez, coloca em tensão a relação entre o movimento espírita, as práticas assistencialistas e os hospitais psiquiátricos, centrando na trajetória do Hospital Benedita Fernandez e em como através destas relações foi se constituindo o atendimento à saúde mental na cidade de Araçatuba, a partir dos anos de 1930.

O quarto artigo desta seção, cuja autora é Soraya Fleischer se intitula "Especiais" e "rebeldes": práticas governamentais da gestão da pressão alta em um bairro popular do Distrito Federal. A autora foca nas políticas públicas da gestão da pressão alta, num bairro da Cinelândia (DF), colocando sob análise moralidades que estigmatizam as pacientes como "rebeldes" ou "especiais" dependendo o grau de acatamento que as mesmas têm em relação à aplicacao das politicas de saude.

Maynara Costa e Rozeli Porto, no artigo Negociações do corpo: reflexões sobre o acesso ao aborto legal em uma maternidade potiguar, analisam as representações das profissionais de saúde do Programa de Assistência às Vítimas de Abuso Sexual, na capital do Rio Grande do Norte, sobre as práticas de aborto legal como consequência de estupros, principalmente a denominada objeção de consciência, ratificando uma "burocracia processual" que evidencia um conflito entre a norma e a subjetividade nos atendimentos, através do qual o corpo da mulher é alvo do poder da equipe de saúde interveniente.

Por fim, o último artigo da Parte I, Os muros do Estado: dos limites da política reparatória aos atingidos pela hanseníase, de Glaucia Maricato, através de um percurso histórico da problemática, propõe uma reflexão sobre o reconhecimento de sujeitos atingidos pela hanseníase e a articulação com as políticas reparatórias e acesso a direitos, e como interferem neste debate noções como ordenamento, delimitação, segregação e padronização desses sujeitos.

A Parte II: Agenciamentos e experiências sociais em saúde deste livro, pretende focar nas discussões sobre as práticas dos sujeitos, seus processos de cura e de autocuidado, junto com suas resistências, problematizando os saberes desses sujeitos e a produção dos regimes de verdades institucionalizados nos processos de saúde-adoecimento. Cabe destacar que a partir deste eixo aparecem com maior preponderância as posições de sujeito que incorporam a categoria de agenciamento descrita alguns parágrafos anteriores.

Jociara Alvez Nóbrega descreve no seu artigo "Doença dos magros": mobilização social e busca por reconhecimento envolvendo uma síndrome rara no Rio Grande do Norte, a disputa por direitos de mães de pessoas com a síndrome de Berardinelli. Se valendo do conceito de biopoder de Foucault, a autora analisa as tensões entre saúde, direitos e justiça que se articulam ao redor da luta pelo reconhecimento biossocial das pessoas que padecem a doença.

O artigo "Eu tô fazendo certo, tô não?": envelhecimento, políticas de saúde e relações de cuidado, de Marcia Reis Longhi, traz reflexões sobre a aplicação das políticas públicas de saúde e as estratégias de autocuidado entre pessoas idosas na Comunidade da Guia (PB), privilegiando uma perspectiva interseccional (incorporando para a análise as categorias de gênero, raça, geração). Cabe destacar que a proposta da autora reivindica o entendimento do termo cuidado numa "perspectiva polissêmica, dinâmica e relacional”.

O terceiro artigo que compõe a parte II deste livro foi escrito por Rosa Virginia Melo e intitulado Ajuda mútua, comunidade terapêutica e a regulação moral dos adictos, aporta reflexões sobre o regime de produção de verdade em relação 
à "doença da dependência química" e o tratamento da mesma em complexos terapêuticos de inspiração religiosa, no Distrito Federal. Por sua vez, a autora problematiza neste artigo as estratégias do sujeito "dependente químico" para se encaixar na proposta de tratamento e cura destas instituições.

Mario Eugenio Saretta, autor de Efeitos ontológicos ao feitio antropológico: consequências de uma etnografia em um hospital psiquiátrico, baseado em experiências etnográficas em Porto Alegre, problematiza o funcionamento de uma instituição psiquiátrica e as formas desta de lidar com o outro diferente (pacientes), com a proposta de descentrar a utilização de categorias psiquiátricas a priori para sua análise e refletindo em relação aos aportes que a antropologia pode fazer neste contexto.

No quinto artigo desta seção, Loucura e doença mental no contexto da política pública de saúde mental no Brasil, Ana Paula Muller de Andrade discute, a partir da recuperação da trajetória da reforma psiquiátrica no país, a articulação entre loucura e doença mental "no âmbito dos processos de desinstitucionalização de pessoas acometidas por algum tipo de sofrimento mental", resgatando as experiências dos sujeitos, através de uma pesquisa etnográfica realizada em Pelotas (RS).

Por último, no sexto artigo desta secção e sendo o último artigo deste livro, Maria Audirene de Souza Cordeiro e Deise Lucy Oliveira Montardo, no texto intitulado "Um corpo mar gerado, mar formado, é um corpo doente, sim senhora": os resguardos de corpo e de boca e a construção de corpos saudáveis no Baixo Amazonas, discutem, a partir de uma experiência etnográfica em Parintis (AM), práticas ao redor de mulheres grávidas. A análise destas autoras resgata as práticas descritas no artigo de sua autoria, principalmente práticas de resguardo do corpo físico e moral, como "rito de passagem". Por último, cabe destacar que este artigo também problematiza as tensões entre as práticas "nativas" e as práticas institucionalizadas de saúde e as estratégias dos e das sujeitos/as para combinálas.

A partir do descrito até aqui fica evidente que este livro está composto por diversas e ricas experiências etnográficas o que lhe outorga um diferencial difícil de superar. Nele diversos conceitos chave do campo da saúde, como o são loucura, doença, corpo, políticas públicas, autocuidado, cuidado, entre outros, são apresentados e se configuram de maneira diferente a partir de cada experiência de campo e de cada um/a das/dos interlocutoras/es. Através de cada uma de suas experiências, as autoras têm ressignificado termos que são chave para traçar a história das políticas de saúde no Brasil e para pensar em novas perspectivas e propostas à luz dos diferentes cenários possíveis do Brasil atual e futuro. Estes múltiplos e diversos olhares, por sua vez multissituados num senso duplo (a partir de diferentes trajetórias e desde diferentes lugares geográficos), resgatam a voz do "nativo" de cada experiência e o recolocam no lugar de centralidade que lhes corresponde.

Recebido em 12 de fevereiro de 2019. Aprovado em 17 de maio de 2019. 